\title{
OSS and ERP Systems: Likeness, Difference and Reference
}

\author{
Jiayin Qi, Huaying Shu, and Kaili Kan \\ Economics and Management School, Beijing University of Posts and \\ Telecommunications, $10 \mathrm{Xi}$ Tu Cheng Road, Haidian District, Beijing, \\ China, 100876 \\ ssfajy@263.net, \\ shuhy@bupt.edu.cn, \\ kankaili@yahoo.com, \\ WWW home page: http://www.sem.bupt.cn
}

\begin{abstract}
With similar motivations and functionalities, ERP and OSS play the same role as integrated IT platforms in manufacturing and telecommunication operations respectively. However, business processes, supply chains and resources in these two industries differ significantly. Therefore, OSS becomes the IT platform for telecommunication operations, and thus rejecting ERP's proclaimed universal applicability among all industries. However, as numerous similarities exist between ERP and OSS systems, valuable experience from ERP's research and development could still be applied to those of OSS.
\end{abstract}

\section{Introduction}

Enterprise resource planning (ERP) systems may be regarded as one of the most innovative developments in information technology (IT) of the 1990s [1]. Although the market of ERP continues to increase [2], its application concentrates in manufacturing and related industries [3].

As a high tech service industry, telecommunications closely combines business processes and IT applications, for it is very important to use IT support systems to improve operators' competitiveness. However, while there is a vast requirement for IT systems among telecommunication operators, the application of ERP systems is still limited to telecommunication equipment manufacturing. On the other hand, ERP solutions for telecommunications operators by SAP, Oracle/PeopleSoft and SSA are more similar to customer relationship management (CRM) systems instead of ERP systems.

Please use the following format when citing this chapter:

Qi, J., Shu, H., Kan, K., 2006, in Intcrnational Fedcration for Information

Processing, Volume 205, Research and Practical Issues of Enterprise Information Systems, cds.

Tjoa, A.M., Xu, L., Chaudhry, S., (Boston:Springer), pp.457-466. 
Provided by TeleManagement Forum (TMF), operations support system (OSS) is the mainstream technology to support large-scale network's operation, maintenance and management and is adopted by more and more telecommunications operators.

Some people view ERP as the mapping of all processes and data of an enterprise into a comprehensive integrated computer software, as well as the key element of an infrastructure that delivers a solution to businesses of multiple industries (including telecommunications) with very different characters [4]. Therefore, some scholars believe the term ERP is too narrowly focused, and suggest to replace the term ERP with the term business system (BS) [5] or enterprise-wide planning of resources [6]. On the other hand, some scholars consider ERP as the development of IT support for manufacturing, with the basic thought as supply chain management [7]. This second opinion probably better explains why ERP so far has not become the basic software system for telecommunication operators, for supply chain management is not the key character of telecommunication operations.

Although OSS has been widely accepted by telecommunication operators, much remains to be done, especially academic research in OSS. By analyzing above issues, this paper compares the similarities and differences between OSS and ERP systems. Their similarities may lend experience from research and application of ERP to those of OSS, while their differences may explain why telecommunication operators choose OSS instead of ERP systems.

\section{The Concepts of ERP and OSS}

As the first approach to combine business management and IT concepts [8], ERP systems are comprehensive software packages that integrate the complete range of a business processes and functions in order to present a holistic view of the business from a single information and IT architecture. Most ERP systems automate corporate core activities such as manufacturing, human resource, finance and supply chain management [7].

OSS generally is a term for the collection of all support systems required to run a telecommunication operators' business. Its four functions can be characterized by operation support, business support, resource support and system support [9]. Operation support system consists of CRM, operation analysis and decision support, office automation and human resource management etc. Business support system includes marketing \& sales, call center, service fulfillment, order management and billing etc. Resource management system has network resource management, operation information management, customer basic information management and customer service information etc. Similar to any other systems, system support system deals with log file, system parameters, etc. 


\section{Similarities between ERP and OSS}

Although ERP and OSS are different, they have some similarities.

\subsection{Similar implementation motivations}

Motivations of ERP and OSS both concentrate on common platform, cost reduction, better customer service and process reengineering.

- Common platform: uniform software platform is the most important motivation of the implementation of both ERP and OSS [10,11].

- Cost reduction: cost reduction through operation automation is the common goal of ERP and OSS [10,12].

- Better customer service: rapid development and timely deployment of new services are both important in ERP and OSS [10, 13].

- Process reengineering: business process integration is the concern of both ERP and OSS [10, 14].

\subsection{Similar characteristics}

Modularization, business process-specific, integration and management thought are the main characteristics of both ERP and OSS.

- Modularization: Most available ERP packages are structured into different modules [10], typically including accounting, human resource, manufacturing and logistics. The structure of OSS systems is modularized according to the telecommunication operation as well.

- Business process-specific: Each module is business process-specific. The use of ERP is associated with business engineering (BE) and the optimization of business processes [10]. OSS realizes the end-to-end customer business operation processes, which will inevitably bring business process reengineering as well [15].

- Integration: An ERP system creates an enterprise-wide transaction structure by integrating modules, storing and retrieving processes of data, management and analysis functionalities [10]. On the other hand, as the goal of OSS is to improve the quality of customer service, it effectively integrates the sub-systems of all business sections into a single system as well.

- Implementation of management: Both ERP and OSS are not merely software systems, but are the implementation of management. Therefore, successful ERP and OSS systems are not a choice of software packages, but are the implementation of competitive strategy, corporate culture, business process reengineering (BPR), management support, training, etc. 


\subsection{Similar roles}

It can be seen from the concepts of ERP and OSS that they are both integrated software solutions to enterprises, although ERP systems are mostly for the manufacturing industry while OSS is usually for telecommunication operators. In general, ERP and OSS systems are both the most important software platform in these enterprises, and both significantly increase their competitiveness. In this sense, OSS is the ERP system for telecommunication operators.

\section{Differences between ERP systems and OSS}

On the other hand, the reason that telecommunication operators choose OSS instead of ERP systems lies in the difference between ERP and OSS.

\subsection{Different operation process}

If an enterprise is considered as a system, its operation is considered as a process which transfers internal resources of this enterprise into products needed by its market under certain conditions.

For manufacturing industries, input of the operation process is raw material. The enterprise gets raw materials from suppliers, turns them into all kinds of fittings through machining, puts the fittings into production lines according to a fixed procedure, and finally makes the finished product enter customer market. Information flow, material flow (logistic) and financial flow run through this process.

Fig. 1 shows this operation process. Demand information flows from the customer market into the direction of supplier market, and affects the decision of each step. This causes the output of the enterprise system close to customer's requirement. Material flows from the supplier market into the direction of customer market and makes a value-added process. The financial flow exists within the material flow. The material flow is central to the entire process, although the other two are also important.

As for telecommunication operation, output of the enterprise is information services instead of tangible goods, while input of the operation process is service requirement information from its customer market. According to service requirements, the telecommunications operator invests in and builds its networks in order to meet these requirements. These new businesses are packaged to be service product, which then is sold to customer market.

Fig. 2 presents this process. Service flow, information flow and financial flow are the basic flows in telecommunications operator's operation process. Customer requirement information flow begins at customer market, and ends at the first step of operation process. The service flow begins at the second step and ends at customer market. The financial flow goes with service flow. Obviously, the core flow is 
service flow, while its efficiency is very important to compose the core competitiveness of this telecommunication operator.

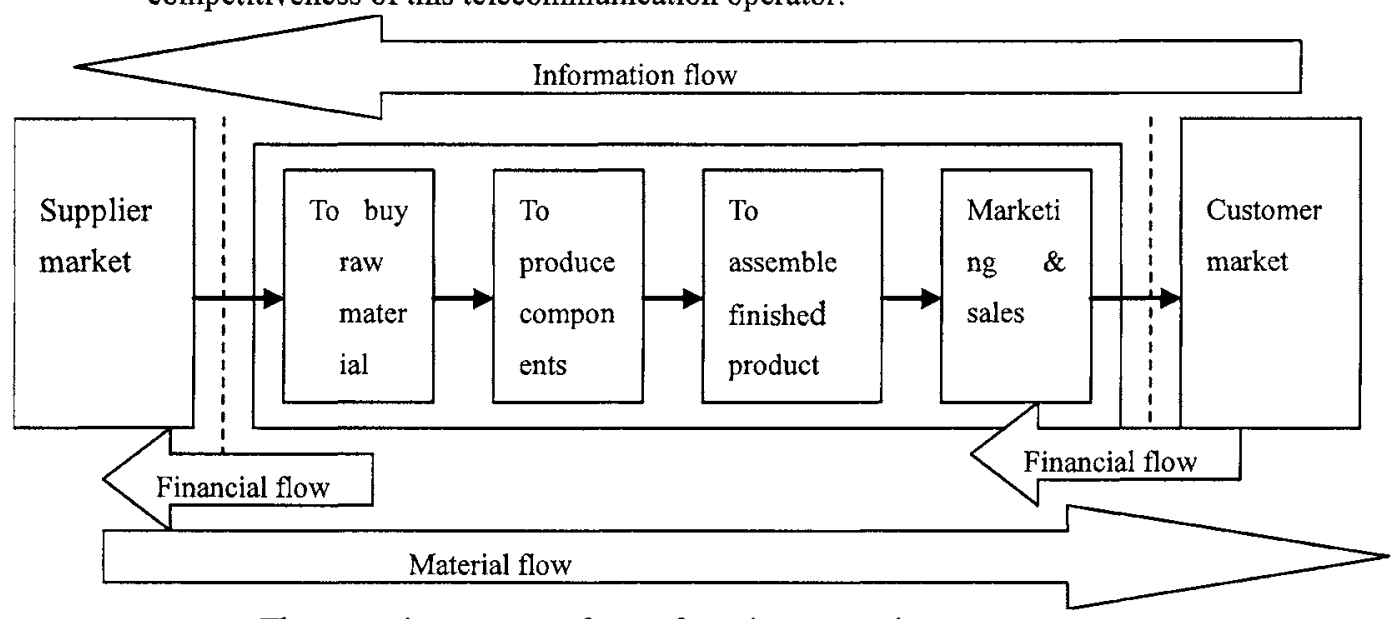

Fig. 1. The operation process of manufacturing enterprise

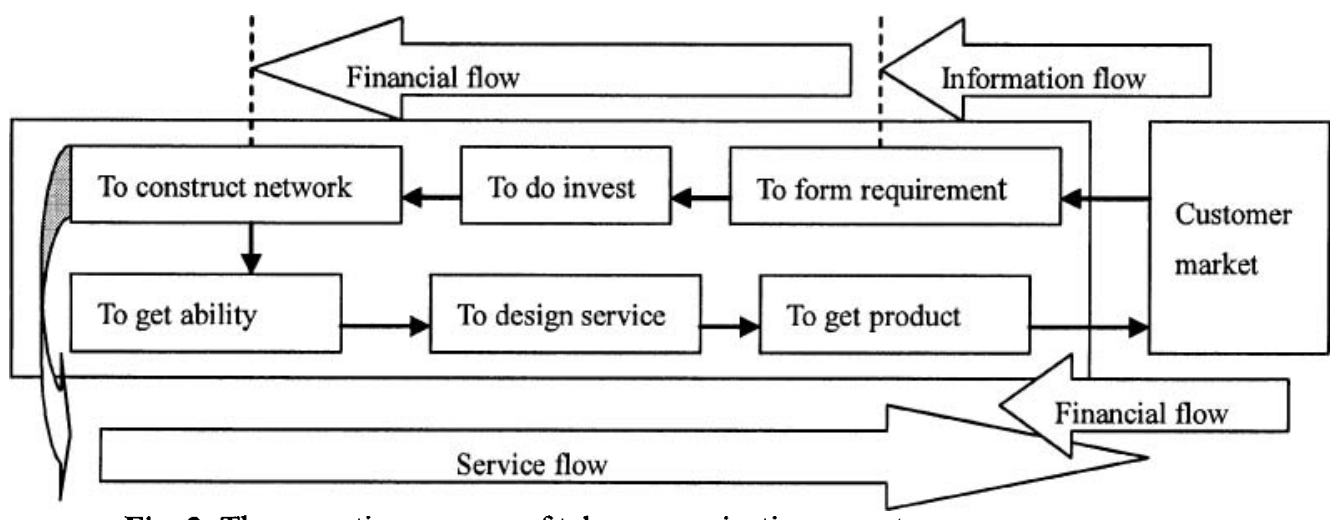

Fig. 2. The operation process of telecommunication operators

One of the most important OSS packages is eTOM, which specifically deals with customer service flow. This confirms OSS is effective for supporting service flow, while ERP systems primarily deal with material flow.

\subsection{Different value chain}

Both ERP and OSS must support the value chain of the enterprise in order to enhance its competitiveness. However, different value chains require different IT platforms.

Porter's value chain model is widely used in manufacturing industry. In this model, inbound logistics, operations, outbound logistics, marketing \& sales and 
service are the primary activities, while procurement, human resource management, financial management, technology development and corporate infrastructures are the support activities. All these activities together provide customer value. Porter's value chain model is shown in Fig. 3.

\begin{tabular}{|c|c|c|c|c|c|}
\hline $\begin{array}{l}\text { Primary } \\
\text { activities }\end{array}$ & $\begin{array}{l}\text { Inbound } \\
\text { Logistics }\end{array}$ & Operations & $\begin{array}{l}\text { Outbound } \\
\text { Logistics }\end{array}$ & $\begin{array}{r}\text { Marketing } \\
\& \text { Sales }\end{array}$ & Service \\
\hline \multicolumn{6}{|c|}{ Procurement } \\
\hline \multirow{4}{*}{$\begin{array}{l}\text { Support } \\
\text { activities }\end{array}$} & \multicolumn{5}{|c|}{ Human Resource Management } \\
\hline & \multicolumn{5}{|c|}{ Finance Management } \\
\hline & \multicolumn{5}{|c|}{ Technology Development } \\
\hline & \multicolumn{5}{|c|}{ Firm Infrastructure } \\
\hline
\end{tabular}

Fig. 3. The value chain model of manufacturing enterprise

Instead, the value of a telecommunication operator is created by its operation management. Primary activities include new service development, engineering construction, network resource management, network maintenance, billing management, order management, marketing \& sales and customer services [12]. Support activities are technology development, human resource management, financial management and corporate infrastructures. Fig. 4 shows the value chain model of a telecommunication operator.

\begin{tabular}{|c|c|c|c|c|}
\hline \multirow{4}{*}{$\begin{array}{l}\text { Primary } \\
\text { activities }\end{array}$} & \multirow{2}{*}{$\begin{array}{l}\text { New service } \\
\text { development }\end{array}$} & Network resource management & \multirow{4}{*}{$\begin{array}{l}\text { Marketing } \\
\& \text { sales }\end{array}$} & \multirow{4}{*}{$\begin{array}{l}\text { Customer } \\
\text { service }\end{array}$} \\
\hline & & Network resource maintenance & & \\
\hline & \multirow{2}{*}{$\begin{array}{l}\text { Engineering } \\
\text { construction }\end{array}$} & Billing & & \\
\hline & & Order management & & \\
\hline \multirow{4}{*}{$\begin{array}{l}\text { Support } \\
\text { activities }\end{array}$} & \multicolumn{2}{|c|}{ Technology development management } & & \\
\hline & \multicolumn{2}{|r|}{ Human resource management } & & \\
\hline & \multicolumn{2}{|r|}{ Finance } & & \\
\hline & \multicolumn{2}{|r|}{ Firm Infrastructure } & & \\
\hline
\end{tabular}

Fig. 4. The value chain model of telecommunication operator

Activities related with material flow play a central role in the value chain of manufacturing, while there are few material related activities in a telecommunication operator's value chain. Instead, they are replaced by network resource management, network maintenance and billing management, which are entirely different from manufacturing. 
Because the value chain model of telecommunication operation is different, ERP systems have limited support to its primary activities. On the other hand, the eTOM model includes almost all the activities in the value chain of a telecommunication operator. This makes OSS the IT platform for telecommunication operators.

\subsection{Different resources management}

Enterprise resource refers to all resources supporting its business operation and strategy implementation, including human resource, capital resource and infrastructure resource, whereas infrastructure resource includes not only buildings, equipment, etc., but also large scale software systems. An enterprise-level IT platform should manage enterprise resources efficiently.

Comparing a manufacturing enterprise and a telecommunication operator, the most different resource is infrastructure resource. Multiple networks constructed for various services are the core resource for telecommunication operation. This network resource does not exist in manufacturing, so that corresponding modules neither exist in ERP systems. Resource support system is one of the four software packages of OSS, and the network resource management is one of the core functions of resource support system. Therefore, from the resource management view, OSS becomes the integrated IT solution for telecommunication operators.

Problems often complained about ERP systems include limited functionality, lack of decision support, lack of extended enterprise support, implementation and upgrade difficulties, and high total cost of ownership [16]. However, these are not the main reason that telecommunication operators do not choose ERP systems. Instead, differences in operation processes, value chain management and resource management are the real reasons.

Some ERP vendors provide specialized ERP systems for telecommunication operators. However, they are only pieces of application software to parts of the operation management. As core functions in ERP systems do not support the core operation flow, core value activities and core resources, ERP systems cannot become the fundamental software platform for telecommunication operators, while only OSS can play this role.

\subsection{Different development entities}

In addition to the above, as OSS development requires in depth knowledge of the telecommunication operation, its development is usually conducted by telecommunication operators themselves or in close corporation with system developers. This is in sharp contrast with ERP, where enterprises often outsource such developments to system developers or procure ready-made systems. 


\section{Applying ERP experience for OSS development}

As ERP has a longer history and broader application than OSS, it has accumulated more experience in its research and development that can be utilized for those of OSS. A taxonomy framework of ERP research was presented by AI-Mashari [17]. Based on the similarity and differences between ERP and OSS, we get the following taxonomy of OSS research:

- Software platform research: NGOSS, eTOM and methodological aspects are three hot research areas.

- Business process research: Business process management is one of the most important areas of research in OSS.

- Implementation research: The implementation of OSS is an important area of research although little work is done so far.

- Management research: Dramatic changes occur in the telecommunication industry and much work needs to be done in performance management, investment management, knowledge management, etc. $[18,19]$. Consequently, changes need to be made in OSS while much remains to be done.

Different from the research taxonomy of ERP systems [17], supply chain reengineering does not appear in the taxonomy of OSS research. Taxonomy of OSS research is as shown in Fig. 5.

\begin{tabular}{|c|c|c|}
\hline \multirow{4}{*}{$\begin{array}{l}\text { OSS } \\
\text { Research }\end{array}$} & $\begin{array}{l}\text { Software } \\
\text { platform }\end{array}$ & $\begin{array}{l}\text { NGN \& OSS; eTOM \& OSS; NGOSS; Methodological aspects of OSS; } \\
\text { OSS in IS curriculum, etc. }\end{array}$ \\
\hline & $\begin{array}{l}\text { Business } \\
\text { process }\end{array}$ & $\begin{array}{l}\text { Process-based IS Analysis \& Design management; Standardization \& } \\
\text { Flexibility; Business process management, etc. }\end{array}$ \\
\hline & $\begin{array}{l}\text { Implemen } \\
\text { tation }\end{array}$ & $\begin{array}{l}\text { Training \& Teaching OSS; Technical aspects of implementation; } \\
\text { Successful \& Failed implementation; Benchmarking best implementation; } \\
\text { Role of IS function in implementation; OSS for other business, etc. }\end{array}$ \\
\hline & $\begin{array}{l}\text { Management } \\
\text { thought }\end{array}$ & $\begin{array}{l}\text { Performance management; Invest evaluation; Knowledge management; } \\
\text { Risk management; Change management; Deploy strategy; Project } \\
\text { management infrastructure; OSS \& competition, etc. }\end{array}$ \\
\hline
\end{tabular}

Fig. 5. Taxonomy of OSS research

As can be seen, most areas in the taxonomy of OSS are not fully studied, while much work has been done in most areas of the ERP research taxonomy. Therefore, 
although not be listed in this paper, it is obvious that, excluding a few areas such as NGN, NGOSS, etc. that are specific to OSS, research experience of ERP in most areas can be utilized in corresponding research areas of OSS.

\section{Conclusions}

Service flow instead of material flow; service value chain instead of production value chain, and network resource management instead of material resource management, all these industry specific characters make OSS the platform of choice for telecommunication operators. In comparison to the taxonomy of ERP research, taxonomy of OSS research is also provided in this paper. However, on the other hand, due to numerous similarities between ERP and OSS systems, research in these two areas can learn from each other.

Through this comparative study of ERP and OSS, it can also be concluded that ERP systems are not universally applicable to all industries although it is commonly deployed in manufacturing. For specific industries, ERP's accessory modules are often modified in order to build specific ERP systems while its core modules are left intact. However, for industries with characters vastly different from manufacturing, for example telecommunications and the electric power industry, ERP's core modules need to be modified or replaced by completely new modules. In this case, ERP systems are hardly ERP anymore, unless all the systems that can provide an integrated enterprise solution are defined as ERP systems. However, under this definition, OSS is exactly the "ERP" system for telecommunications operators, while the original ERP system can no longer play the role as ERP.

In general, OSS not only works for telecommunications, but also for other industries whose characters resemble telecommunication operation with network resources, service flow and value chain instead of material flow and production value chains. Examples of these include large power plants [20], traffic management [21], etc. [22], although some modification could be necessary in order to make OSS industry specific.

This paper attributes to "ERP for various businesses" in the taxonomy of ERP research [17]. As the authors just analyze telecommunications industry, it is difficult to answer how far can ERP systems extend? It is important for clarifying the concept and definition of ERP systems. System methodology is useful for this research. But in this paper, it is not expressed due to the aim of the authors. This is the limitation of this paper and is one of the future research directions.

\section{Acknowledgement}

Research of this paper is funded by the National Natural Science Foundation of China (Project No.70371056) and the Key Laboratory of Information Management \& Information Economy of Ministry of Education of the People's Republic of China. 


\section{References}

1. M.L. Markus, D. Petrie, and S. Axline, Bucking the Trends: What the Future May Hold for ERP Packages, Information Systems Frontiers 2(2), 181-193 (2000).

2. Feb. 5, 2005; www.industry.ccidnet.com/pub/article/c32_a202859_p1.html.

3. Dec. 21, 2005; www.erp.com.cn/html/news/erpmarket.htm.

4. H. Klaus, M. Rosemann, and G.G Gable, What is ERP? Information Systems Frontiers 2(2), 141-162 (2000).

5. S. Pawlowski and M.C. Boudreau, Constraints and Flexibility In Enterprise Systems: A Dialectic Of System And Job, Americas Conference on Information Systems, August 13-15, Milwaukee, WI, 1999.

6. S.H. Chung and C.A. Synder, ERP Initiation---A Historical Perspective, Americas Conference on Information Systems, August 13-15, Milwaukee, WI, 1999.

7. N. Gibson, C. P. Holland and B. Light, Enterprise Resource Planning: A Business Approach to Systems Development, IEEE Journal on selected areas in communications, 1-9 (1999).

8. M. Al-Mashari, A. Al-Mudimigh and M. Zairi, Enterprise Resource Planning: A Taxonomy of Critical Factors, European Journal of Operational Research 146, 352-364 $(2000)$.

9. T.J. Lv, N. Yang, and H.J. Wu, Operation Support Systems----Theory, Strategy And Practice (Renmin Post \& Communications Press, Beijing, China, 2003).

10. J. W. Ross, M. R. Vital, The ERP Revolution: Surviving vs Thriving, Information Systems Frontiers 2(2), 233-241(2000).

11.J. J. Appel, M. J. Polosky, Pacific Bell's Network and Systems Concept of the 90's, IEEE Journal on selected areas in communications, 6(4), 627-632 (1988).

12. Ji-Tsu Wu, Been-Hwang Liao, Chi-Yuan Wu, The Operations Support Systems for Transmission Network in Taiwan, IEEE Journal on selected areas in communications 12(4), 1-4 (1997).

13.H. Everitt and M. Virgin, Full Services Network Operations and Management, IEEE Journal on selected areas in communications 23(3), 1-10 (1996).

14. Q.J. Xia and M. Rao, A Hybrid Intelligent System for Process Operations Support, IEEE Journal on selected areas in communications 2097-2102 (1997).

15. The-sheng Huang, Chia-chen Lee, and Yu-mei Chen, A New Architecture To Operation Support Systems, IEEE Journal on selected areas in communications 1236-1242 (2003).

16. M.L. Markus, D. Petrie and S. Axline, Bucking the Trends: What the Future May Hold for ERP Packages, Information systems Frontiers 2(2), 181-193(2000).

17. M. Al-Mashari, A. Al-Mudimigh and M. Zairi, Enterprise Resource Planning: A Taxonomy of Critical Factors, European Journal of Operational Research 146, 352-364 (2003).

18. R.V. Olst, I.G. Kennedy and P. Chitamu, How Will the New Entrant Telecommunications Operator Benefit From Being New? IEEE Journal on selected areas in communications 461$466(2002)$.

19. John, B. Sugla, and H. Krishnan, An architecture for provisioning IP services in an operations support systems, IEEE Journal on selected areas in communications, 455-458 (2003).

20.Q.D. Feng and Y.J. Cao, Models of electric market operation support system based on UML, IEEE Journal on selected areas in communications 13-18 (2001).

21.H. Takahashi, A Study On Designing Driver's Operation Support System Using Driving Environment-Driver-Vehicle Interaction Model, IEEE Journal on selected areas in communications 177-182 (1998).

22.M.H. Sherif and S. Ho, Evolution of Operation Support Systems in Public Data Networks, IEEE Journal on selected areas in communications 72-77 (2000). 